\title{
Aplikasi Drone Militer Dengan Produk Alutsista Indonesia untuk Over the Horizon Operations
}

\section{(Military Drone Applications by Using Indonesian Defense Equipment for Over the Horizon Operations)}

\author{
Denny Lesmana $^{1^{*}}$, Yudha Permana ${ }^{2}$, Budi Santoso ${ }^{3}$, Ardian Infantono $^{4}$ \\ 1,2 Departemen Pengembangan Produk dan Proses, Divisi Inovasi, PT. Pindad (Persero) \\ E-mail: dennyl@pindad.com \\ ${ }^{3}$ Program Studi Teknik Manajemen Industri Pertahanan, Akademi Angkatan Udara, Yogyakarta \\ E-mail: budi.bodjong@aau.ac.id \\ ${ }^{4}$ Program Studi Teknik Aeronautika Pertahanan, Akademi Angkatan Udara, Yogyakarta \\ E-mail: ardian.infantono@aau.ac.id
}

\begin{abstract}
Drones/unmanned aircraft are one of the technologies in the defense sector that are included in the Indonesian government's strategic program. In the era of Information technology and society 5.0, the use of high technology is indispensable in overcoming various problems, especially Indonesia which has a large area. Drones can be a multifunctional platform that can play a role in War Military Operations (OMP) and Military Operations Other Than War (OMSP). The use of drones in the military is generally used as part of "Over The Horizon Operations", where all devices related to operations such as combat vehicles, weapons, and personnel communication tools become one unit in the "Battle Management System". The use of drone technology will be able to reduce the risk of pilots as well as the cost efficiency of their operations. With the flexibility of the role shown by the presence of drones, it can be a solution to various problems related to the needs of the users themselves, such as illegal fishing, illegal immigrants, piracy, floods, forest fires, terrorism, and military infiltration of other countries.
\end{abstract}

Keywords — Drone, Militer, Battle Management System, Operasi, Horizon Operations

Abstrak-Drone/ pesawat tanpa awak merupakan salah satu teknologi di bidang pertahanan yang termasuk di dalam program strategis pemerintah Indonesia. Di era teknologi Informasi dan society 5.0, penggunaan teknologi tinggi sangat diperlukan dalam mengatasi berbagai permasalahan khususnya Indonesia yang memiliki wilayah luas. Drone dapat menjadi platform multifungsi yang dapat berperan dalam Operasi Militer Perang (OMP) maupun Operasi Militer Selain Perang (OMSP). Penggunaan drone di militer umumnya digunakan sebagai bagian dari "Over The Horizon Operations”, dimana semua perangkat yang terkait operasi seperti kendaraan tempur, persenjataan, serta alat komunikasi personil menjadi satu kesatuan dalam “Battle Management System". Penggunaan teknologi Drone akan dapat mengurangi resiko dari pilot maupun efisiensi biaya dari operasionalnya. Dengan fleksibilitas peran yang ditunjukkan oleh kehadiran drone dapat menjadi solusi dari berbagai permasalahan terkait kebutuhan dari pengguna itu sendiri seperti illegal fishing, imigran gelap, pembajakan, banjir, kebakaran hutan, terorisme, maupun infiltrasi militer negara lain.

Kata Kunci_- Drone, Military, Battle Management System, Operation, Horizon Operations

\footnotetext{
*Penulis Korespondensi (Denny Lesmana)
}

E-mail: dennyl@pindad.com 


\section{Pendahuluan}

Tndonesia memiliki luas wilayah sebesar $5.455 .675 \mathrm{~km} 2$ dan $3.544 .744 \mathrm{~km} 2$ di antaranya atau 12/3 wilayahnya adalah lautan. Karena mempunyai wilayah yang luas, Indonesia berbatasan dengan banyak negara, walaupun mayoritas negaranya adalah negara anggota ASEAN. Oleh karena itu diperlukan peralatan utama sistim pertahanan dan keamanan yang handal untuk menjaga wilayah perbatasan baik di daratan, laut maupun udara. Namun hingga saat ini Indonesia masih memiliki ketergantungan yang tinggi dengan negara lain dalam pemenuhan alutsista. Untuk itu perlu dilakukan penguasaan teknologi pertahanan dan pengembangan industri pertahanan nasional dalam mengurangi ketergantungan terhadap impor pasokan alat utama sistem pertahanan (Alutsista) dan kemandirian persenjataan militer Tentara Nasional Indonesia (TNI).

Komite Kebijakan Industri Pertahanan (KKIP) yang dibentuk melalui Undang Undang Nomor 16 Tahun 2012 tentang Industri Pertahanan telah menyusun tujuh program nasional untuk kemandirian peralatan utama sistim pertahanan (alutsista) yaitu pengembangan program jet KFX/IFX, program pembangunan kapal selam, program pembangunan industri propelan, pengembangan roket nasional, pengembangan peluru kendali nasional, pengembangan radar nasional, dan pengembangan medium tank. Kemudian pemerintah juga telah menetapkan kebijakan program prioritas pengembangan teknologi dan industri untuk mewujudkan industri pertahanan yang maju, kuat, mandiri, dan berdaya saing dengan berpedoman pada Peraturan Presiden RI Nomor 8 Tahun 2021 tentang Kebijakan Umum Pertahanan Negara Tahun 20202024 (Jakumhanneg). Sehingga ditambahkan tiga program prioritas lainnya yaitu pengembangan satelit militer, pengembangan penginderaan bawah air, serta program pengembangan pesawat udara tanpa awak.

Teknologi drone merupakan salah satu teknologi yang dapat digunakan sebagai peralatan pendukung maupun dilengkapi oleh persenjataan untuk mendukung operasi militer. Drone tersebut akan dilengkapi dengan beberapa peralatan berteknologi militer untuk meningkatkan kemampuannya menjadi peralatan yang memiliki kemampuan untuk melakukan pengamatan maupun penyerangan. Drone militer menjadi salah satu teknologi terbaru yang telah digunakan dalam perang untuk beberapa tahun terakhir, teknologi tersebut meningkatkan efektivitas dalam peperangan. Namun penggunaan teknologi drone dalam peperangan tidak dapat berdiri sendiri, perlu disiapkan ekosistem produk yang dapat terintegrasi dan saling mendukung.

Integrasi sistem drone dengan peralatan militer lain seperti kendaraan tempur, senjata, munisi, bom dan perlengkapan personil lainnya harus didukung oleh sistem komunikasi dan informasi yang mumpuni salah satunya adalah melalui Battle Management System. Integrasi sistem tersebut akan menjadikan operasi militer memiliki konsep "Over the Horizon Operations" yang mengandalkan pengamatan musuh melalui drone dan dapat melakukan penyerangan dengan sistem senjata drone. Pengembangan persenjataan secara mendiri yang mengarah kepada konsep perang "Over the Horizon Operations" akan meningkatkan kemampuan pasukan Indonesia dalam menghadapi ancaman yang akan muncul di masa yang akan datang.

\section{LANDASAN TEORI}

Media komunikasi pengiriman data untuk tracking pesawat secara real time yang dapat digunakan adalah radio frekuensi, karena pesawat terbang menggunakan udara sebagai media ruang gerak yang sangat luas dan tidak terbatas. Infantono, dkk telah melakukan upaya nyata untuk mewujudkan sistem pelacakan pesawat secara real time adalah melaksanakan penelitian tentang kemampuan dalam perancangan model perangkat aircraft mobile tracking yang memanfaatkan penerima GPS menggunakan media komunikasi radio frequency (RF) dan pembuatan perangkat lunak yang terkait dengan perangkat tersebut [1]. 


\section{A. Drone/Unmanned Air Vehicle}

Di era sekarang, wahana udara tak berawak (UAV) juga dikenal sebagai "drone" seharusnya menjadi salah satu teknologi multivariat dan mutakhir. Mereka masih dalam tahap awal dalam hal adopsi dan penggunaan yang besar [5]. UAV sebagai teknologi baru yang dapat dimanfaatkan untuk aplikasi militer, publik, dan sipil. Penggunaan militer UAV berusia lebih dari 25 tahun, terutama untuk pengawasan perbatasan, pengintaian, dan serangan [6].

Saat ini hingga di masa depan, medan perang kemungkinan akan sangat dinamis, yang mengamanatkan persyaratan untuk mengintegrasikan sensor, penembak, Post Strike Damage Assessment (PSDA) dan kemampuan serangan ulang pada satu platform jaringan. Ini akan memperpendek pengulangan dalam Observe-Orient-Decide-Act (OODA) dan memberikan keunggulan yang menentukan bagi para komandan dalam operasi. Ini adalah area khusus di mana Kendaraan Udara Tak Berawak (UAV) cenderung memainkan peran yang berkontribusi dan menentukan [7].

Salah satu cara untuk melibatkan musuh dengan korban minimal adalah melalui penggunaan UAV. Mereka adalah anggota yang paling terlihat dari keluarga sistem tak berawak dan otonom baik yang digunakan atau sedang dikembangkan. Kendaraan udara bertenaga ini tidak membawa operator manusia, menggunakan gaya aerodinamis untuk mengangkat, terbang secara mandiri atau dikemudikan dari jarak jauh, dapat dibuang atau dipulihkan, dan membawa muatan mematikan dan tidak mematikan [7].

\section{B. Battle Management System}

Sistem komputer memiliki kemampuan dalam menjalankan proses dengan kecepatan yang sangat tinggi, yaitu dalam melakukan processing meliputi image rendering, location detection, data transferring, dan lain-lain hingga melakukan eksekusi dari beberapa perintah program. Sistem komputer tersebut dapat digunakan untuk melakukan simulasi peperangan dimana akan memberikan keuntungan bagi pengguna untuk menerapkan beberapa teori perang maupun strategi-strategi tanpa harus ada musuh yang nyata. Selain dapat difungsikan sebagai simulator pertempuran, komputer dijadikan sebagai media dari komandan untuk mngendalikan pasukan, salah satu contoh nyata yang dapat diterapkan adalah untuk melihat pergerakan pasukan secara nyata melalui komputer, kemudian menyampaikan alur komando melalui sebuah alat yang dimiliki oleh masing-masing prajurit ataupun komandan batalyon di lapangan. Fungsi seperti inilah yang kemudian sistem dapat disebut sebagai Battlefield Management System (BMS) [1]. Battlefield Management System (BMS) adalah sebuah sistem informasi berbasis komputer yang dikembangkan untuk memenuhi kebutuhan decison-making, simulasi perang, analisis, prediksi, pelatihan taktik dan strategi [2].

Dalam sebuah simulasi pertempuran, diperlukan adanya model yang memetakan bentuk aset - aset pertempuran. hal ini jelas diperlukan karena pemodelan merupakan salah satu kontribusi penting bagi berjalannya simulasi pertempuran tersebut Model yang akan dirancang sesuai dengan kondisi aslinya, artinya dalam pembuatan model, terutama model perang harus memeperhatikan keseluhan aspek yang terdapat pada kenyataan, sehingga simulasi dapat berjalan seperti kenyataan [3].

Semua bentuk kejadian ataupun aktifitas yang ada harus dapat dilihat pada BMS tersebut, seperti data intelligent, peta lokasi sekitar pertempuran, banyak pasukan yang tersisa, siapa saja yang gugur, hingga terdeteksinya posisi pasukan musuh. Berbeda dengan BMS, simulator hanya berupa simulasi saja. Data-data pun dapat dibuat sedemikian rupa sehingga dapat disesuaikan dengan kebutuhan simulasi pertempuran yang akan dilakukan [1].

Penerapan sistem BMS pada sistem kendaraan tempur, alat komunikasi personil, maupun teknologi drone militer akan mendukung TNI dalam menerapkan konsep perang masa depan yang dapat diterapkan dalam operasi "Over the Horizon". 


\section{Konsep Perang "Over the Horizon"}

Pada awal berkembangnya teknologi perang, kekuatan perang di udara hanya dijadikan sebagai alternatif untuk mendukung kekuatan perang darat yang telah lama digunakan, Kekuatan udara tersebut digunakan untuk menjaga atau mengambil alih sebuah daerah untuk membatasi atau menhancurkan musuh. Dengan berkembangnya teknologi perang, Angkatan Darat Amerika Serikat melihat pesawat udara sebagai kemampuan tambahan untuk kekuatan darat yang ada, karena informasi dari penerbang akan memberikan komandan pasukan di darat informasi awal kondisi perang. Strategi tersebut menunjukkan bahwa kekuatan udara memiliki keunggulan dalam melihat dan melacak posisi dan pergerakan musuh dengan cepat serta menyediakan komunikasi antara pasukan darat yang sering dipisahkan oleh medan yang tidak dapat dilewati, dan akhirnya memberikan beberapa tingkat serangan udara-ke-darat terhadap target yang dipilih. Teori kekuatan udara ini mengarah pada pengembangan strategi yang selanjutnya menegaskan bagaimana dan mengapa kekuatan udara akan digunakan untuk memenuhi tujuan strategis keuntungan militer dan pada akhirnya kemenangan [4].

Saat ini pengembangan pesawat siluman telah dilakukan dalam beberapa dekade dan anggaran biaya yang digunakan telah mencapai batas atas. Kemudian dengan perkembangan teknologi, dalam operasi perang telah digunakan pesawat yang dikendalikan dari kejauhan dengan kendali pilot yang terlatih serta didukung oleh sistem yang canggih. Pada tahap pengembangan selanjutnya, para pilot tidak lagi mengendalikan pesawat yang berukuran besar, melainkan drone yang berukuran lebih kecil, serta sangat sulit untuk dilacak. Saat ini, UAV atau Drone digunakan oleh militer di seluruh dunia untuk misi intelijen, pengawasan, pengintaian, peperangan elektronik, dan serangan[4]. Di masa depan, mereka dapat digunakan untuk memasok, pencarian dan penyelamatan tempur, pengisian bahan bakar udara dan pertempuran udara. Ketersediaan teknologi navigasi dan komunikasi satelit yang canggih telah membuat pengoperasian UAV jarak jauh menjadi lebih praktis [7]. Dengan kemampuan tersebut drone dapat disebut sebagai ujung tombak dalam konsep perang "Over the Horizon"[4].

\section{ApliKasi Drone MiLITER}

\section{A. Teknologi Drone Militer}

Saat ini, drone terutama memenuhi fungsi intelijen, pengawasan, akuisisi target, dan pengintaian. Ini melibatkan penggunaan berbagai sensor, seperti inframerah, radar, frekuensi radio, termografi, dan suara, untuk mengumpulkan informasi tentang wilayah target, kondisi lokal, dan kemungkinan target, termasuk individu. Ada dua jenis sistem drone yang digunakan untuk periode pengawasan yang lebih lama: drone Medium-Altitude, Long-Endurance (MALE) dan drone High-Altitude, Long-Endurance (HALE). Sistem drone MALE biasanya memiliki ketinggian antara 25.000 dan 50,00 kaki dan dapat berkeliaran hingga 24 jam. Sistem HALE, seperti namanya, dapat terbang setinggi 60.000 kaki dan dapat bertahan selama 32 jam. Namun, ini bukan parameter yang ketat, karena Predator-B, misalnya, dianggap sebagai drone MALE meskipun diiklankan memiliki daya tahan 27 jam. Jenis klasifikasi untuk teknologi drone ini muncul melalui penggunaan utamanya sebagai platform ISTAR, namun, karena tujuan misi utama drone berubah dari waktu ke waktu, sistem klasifikasi mungkin juga beradaptasi [8].

Indonesia sedang mengembangkan drone MALE Kombatan Elang Hitam yang merupakan salah satu program PSN untuk Sektor Teknologi. Drone MALE Kombatan dikembangkan untuk pemenuhan kebutuhan alutsista TNI dalam melaksanakan fungsinya melindungi NKRI dari berbagai ancaman baik dari luar maupun dari dalam negeri. Nilai tambah program pengembangan Drone MALE Kombatan ini lebih ke arah strategis pertahan keamanan. Namun demikian Drone MALE Kombatan dapat juga dikembangkan untuk misi kebutuhan non militer seperti BNPB dan Pemetaan. 
Pengembangan teknologi senjata, amunisi maupun muatan lainnya perlu dikembangkan dengan menggunakan produk alutsista industri pertahanan di dalam negeri. Hal tersebut dilakukan untuk membangun kemandirian industri pertahanan serta kemudahan dalam integrasi sistem serta dukungan perlengkapan maupun suku cadang pendukung.

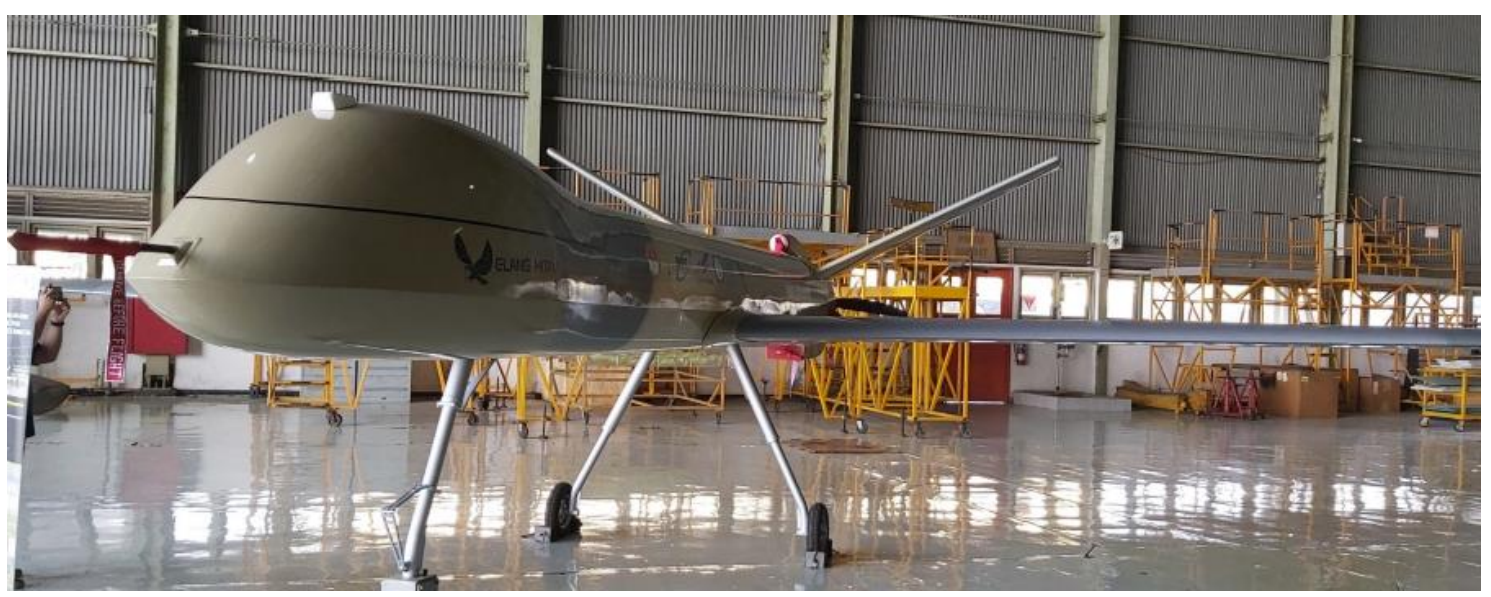

Gambar 1.Drone MALE Elang Hitam

\section{B. Mekanisme Perang “Over the Horizon” Dengan Melibatkan Drone}

Perang menggunakan kekuatan udara akan memiliki keuntungan dari segi efektivitas, kecepatan dan ketepatan dalam penyelesaian operasi. Selain itu perpaduan kekuatan udara seperti pesawat tempur, helikopter bahkan drone dengan fasilitas tempur di darat serta di laut akan memberikan banyak pilihan keputusan dalam sebuah operasi perang. Fungsi drone akan menjadi sangat krusial karena perannya sebagai unit ISRA (intelligence, surveillance, reconnaissance and attack). Drone dapat digunakan dalam menentukan koordinat musuh, melakukan pengamatan lokasi sasaran, bahkan melakukan penyerangan.

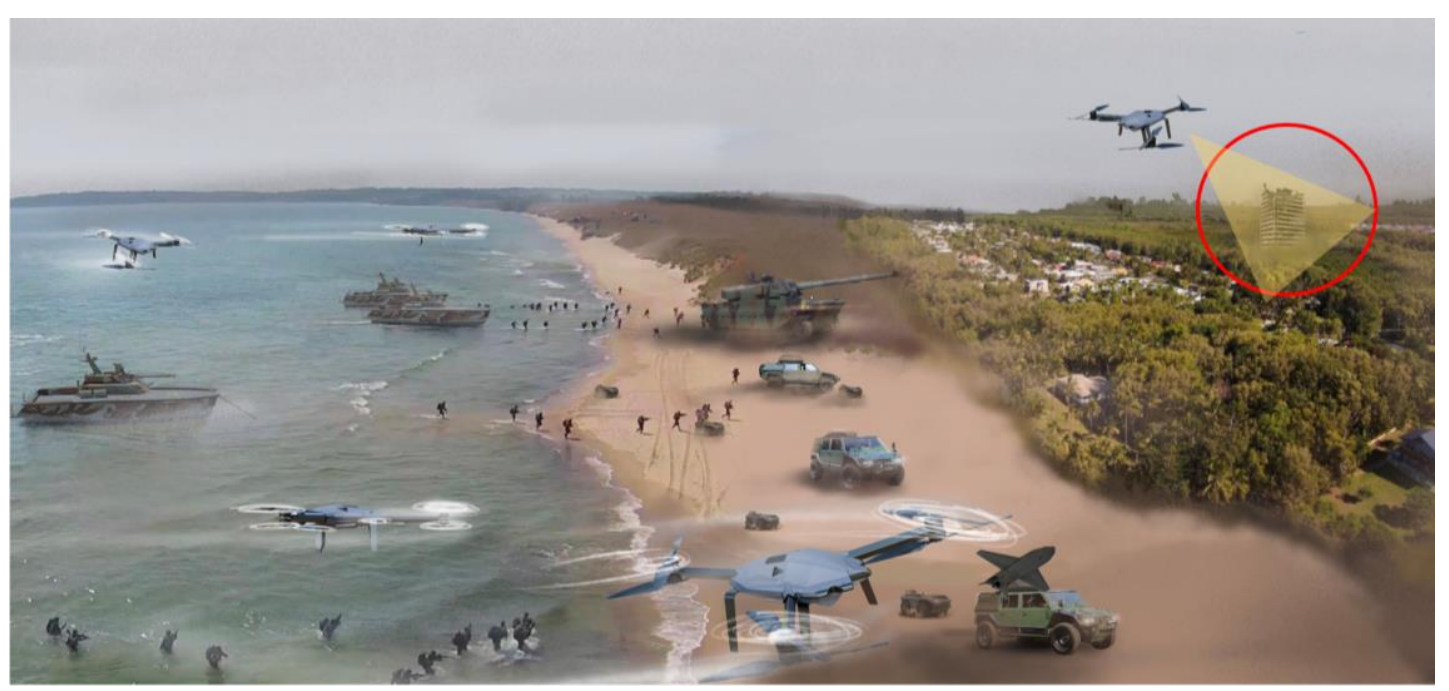

Gambar 2. Proses pengintaian yang dilakukan oleh drone. 


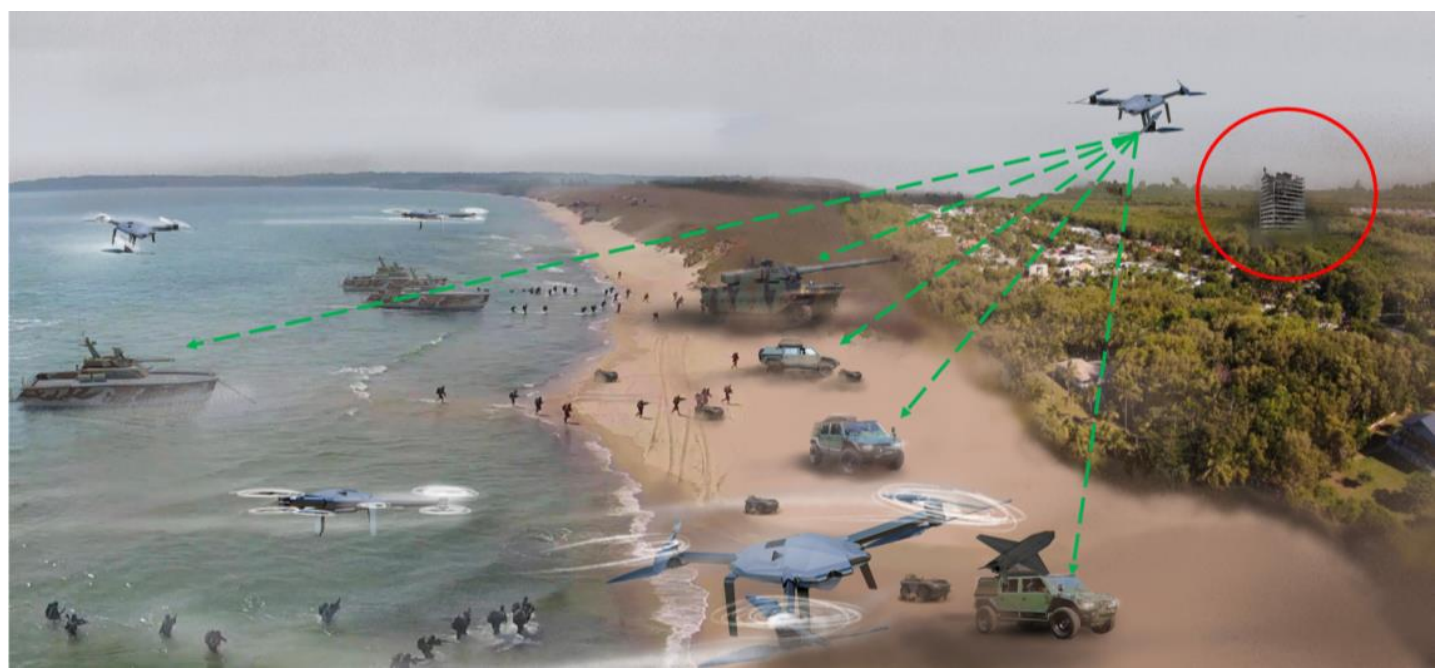

Gambar 3. Distribusi informasi koordinat target kepada komandan pasukan pendukung.

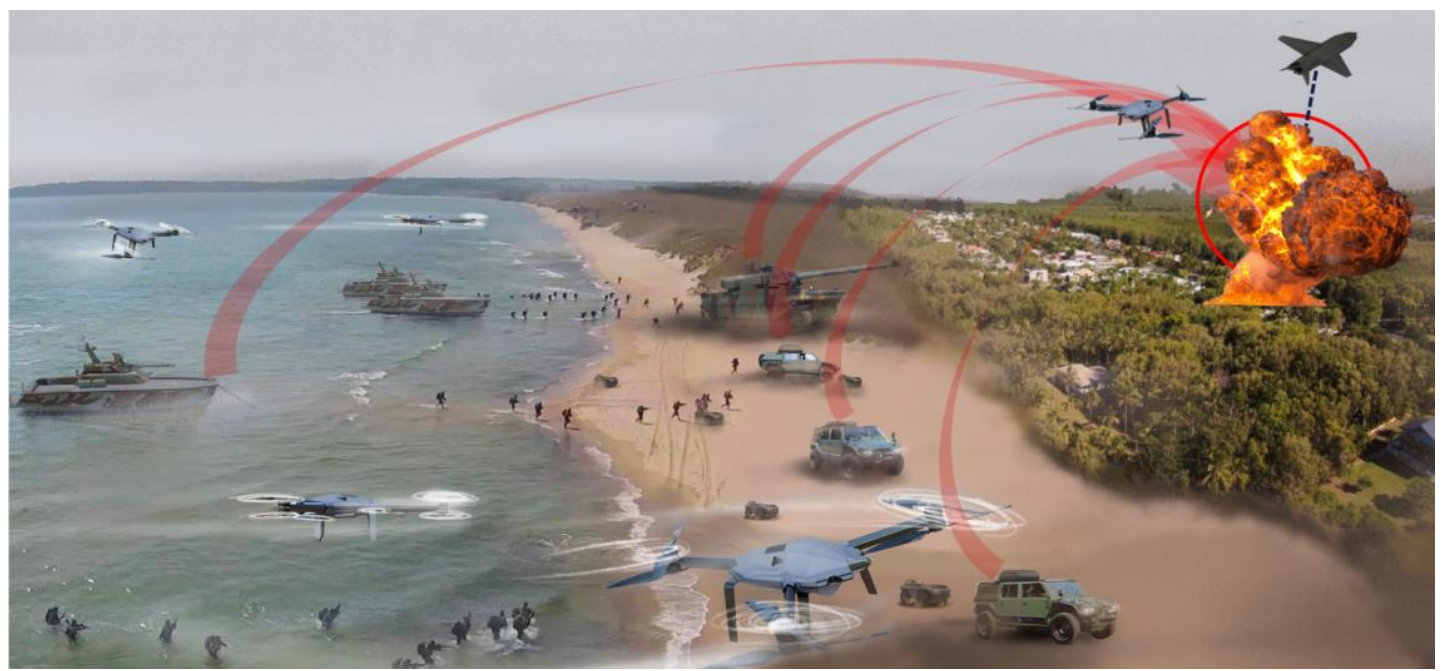

Gambar 4. Serangan ditujukan kepada target dengan koordinat yang telah diinformasikan.

Dalam operasi perang menggunakan konsep "Over the Horizon", drone akan melakukan pengintaian lokasi musuh serta menentukan koordinatnya. Informasi tersebut akan disampaikan kepada masing-masing kesatuan atau komandan operasi hal ini juga umumnya disebut sebagai "Over the Horizon Recognition". Setelah koordinat musuh ditentukan penyerangan dapat dilakukan dengan tepat dan cepat baik menggunakan kekuatan udara (pesawat tempur, bombing drone, Kamikaze Drone, Loitering Drone) sebagai kekuatan utama, serta didukung oleh kekuatan darat (pasukan tank kavaleri, pasukan infantri, atau pasukan armed) dan kekuatan armada laut. Seluruh kekuatan pasukan harus didukung oleh alat komunikasi yang baik serta tersedianya Battle Management System.

\section{Teknologi Pendukung Drone Militer}

\section{A. Teknologi Alutsista Pendukung Drone Militer}

Berbagai jenis drone dapat dipersenjatai dengan beberapa alutsista yang sebelumnya masih digunakan secara konvensional. Pada drone dengan ketinggian terbang rendah dapat 
diaplikasikan beberapa senjata mesin otomatis, senjata pelontar granat, munisi gas air mata, maupun bom $25 \mathrm{~kg}$. Sedangkan pada drone MALE, sistem senjata yang digunakan antara lain laser-guided bomb atau missile yang dapat dikendalikan dengan sistem infra merah atau menggunakan teknologi GPS/INS. Namun ada beberapa drone yang tidak menyerang dengan cara menembakkan peluru atau bom, melainkan menabrakan diri ke target. Drone tersebut umumnya dikenal sebagai Kamikaze Drone (drone bunuh diri), salah satu contohnya adalah Zala Lancet produksi Rusia.
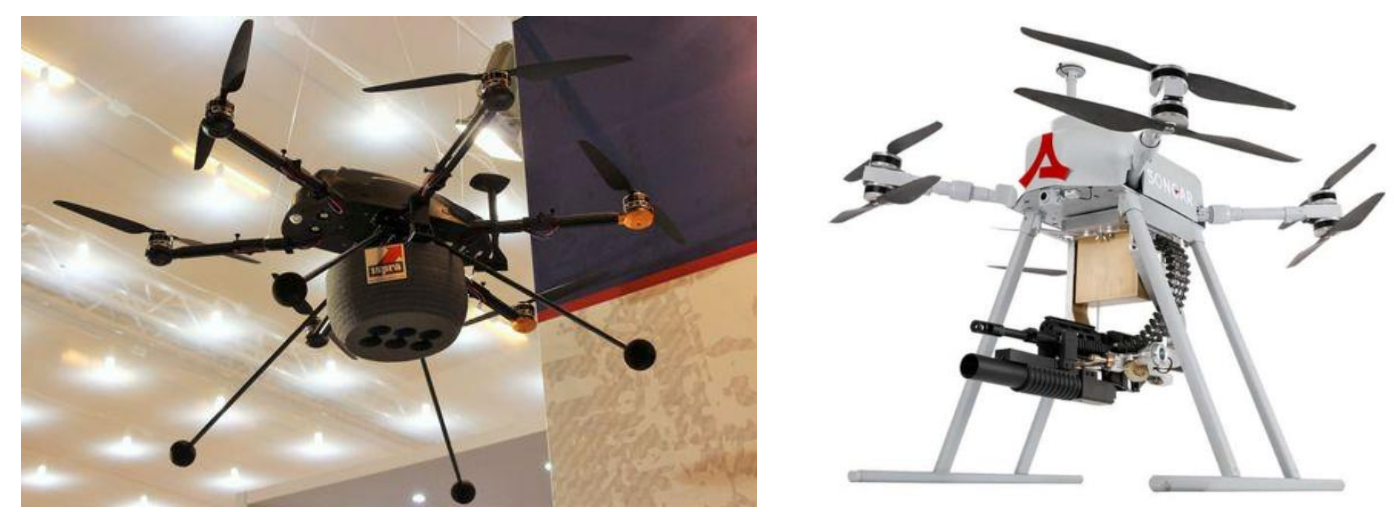

Gambar 5. Tear Gas Drone (kiri), Songar Armed Drone System (Kanan). [9]

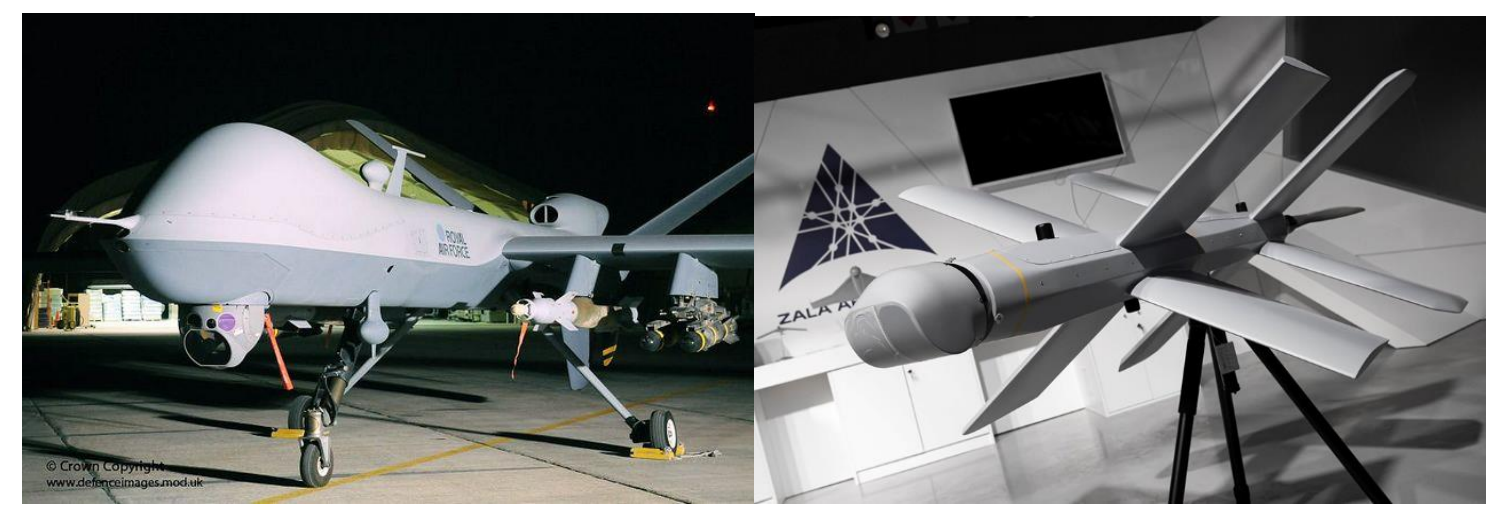

Gambar 6. Senjata Drone MQ-9 Reaper (kiri), Zala Lancet Kamikaze Drone (kanan). [10]

PT. Pindad sebagai salah satu BUMN yang bergerak di Industri Pertahanan telah memproduksi beberapa produk alutsista yang digunakan oleh TNI maupun POLRI. Dengan tujuan mendukung moderinisasi peralatan alpalhankam serta mempersiapkan peralatan untuk sistem pertahanan di masa yang akan datang, PT. Pindad sedang melakukan modifikasi dan integrasi beberapa produk seperti senjata (senapan serbu, senapan otomatis, senjata pelontar granat) dan munisi (munisi $40 \mathrm{~mm}$, granat mortar $60 \mathrm{~mm}$ dan $81 \mathrm{~mm}$, bom $25 \mathrm{~kg}$ ) dengan drone. Selain itu, PT. Pindad juga mendesain kendaraan khusus pembawa dan peluncur drone sebagai peralatan pendukung.

\section{B. Fungsi Pendukung Dalam Operasi Non Militer}

Indonesia setiap tahun memiliki resiko bencana Hidrometeorologi. Dimana menurut Deputi bidang pencegahan Badan Nasional Penanggulangan Bencana (BNPB), Lilik Kurniawan Sebagian besar atau $95 \%$ bencana yang ada di Indonesia punya keterkaitan dengan cuaca dan iklim. Dampak tersebut jika tidak dapat diantisipasi dengan baik tentu bisa mengganggu stabilitas kehidupan bermasyarakat dan ketertiban bernegara. Salah satu teknologi yang digunakan dalam mengatasi permasalahan tersebut yaitu menggunakan bahan penyemai awan, 
dimana kita melepaskan bahan kimia ke dalam awan. Prinsip dasarnya adalah penambahan bahan kimia di dalam awan akan mempercepat penarikan partikel air di udara sehingga awan terlalu berat untuk menahan dan terjadilah hujan. Peningkatan air hujan yang massif akan dapat meningkatkan level air permukaan bersih di suatu wilayah, sehingga teknologi ini banyak digunakan untuk mengisi air waduk atau danau yang mengering.

Teknologi penyemaian awan di Indonesia sudah dimulai sejak tahun 1997 oleh BB-TMC BPPT yang kemudian dilakukan proses manufaktur di Pindad. Kerjasama antara BPPT dan Pindad mulai dilaksanakan pada 2010 dan menghasilkan produk Bahan Penyemai Awan yang diberi nama Cosat 1000.

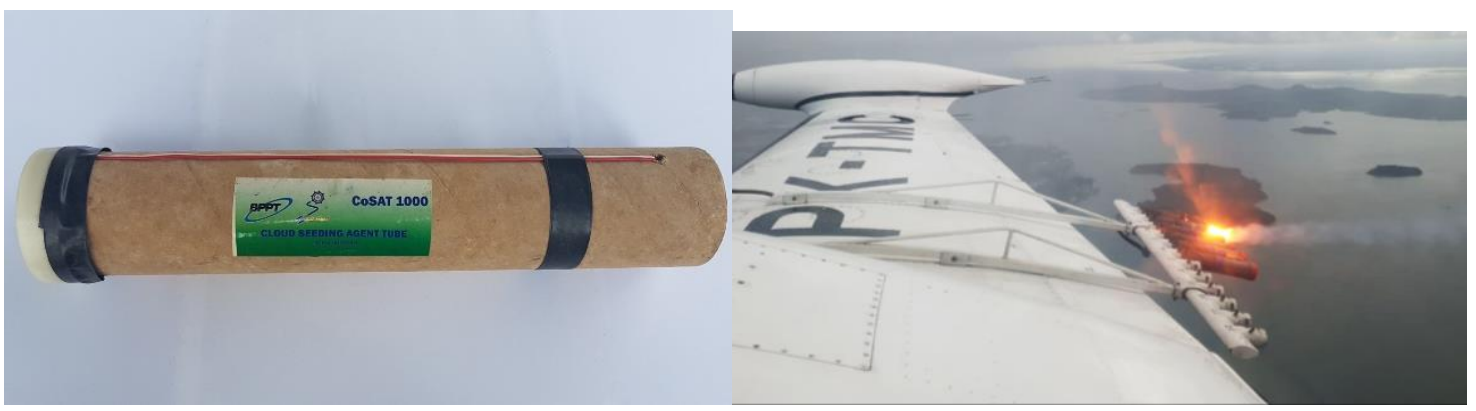

Gambar 7. Produk Cosat 1000 (kiri), Penyemaian Awan (kanan)

Pindad sebagai Industri Pertahanan Nasional tidak hanya dituntut mampu menghasilkan produk untuk kebutuhan Operasi Militer Perang (OMP) namun juga ikut berperan dalam kepentingan Operasi Militer Selain Perang (OMSP). Di dalam konsep Revolutionary Military Affair (RMA), penggunaan produk pertahanan yang mampu dimanfaatkan untuk kepentingan sipil menjadi sangat penting, dimana Paradigma "dual-use" menjadi salah satu kunci dari keberhasilan program RMA [11].

Cosat 1000 adalah salah satu contoh produk yang memiliki kategori "dual use", dimana dimanfaatkan untuk kepentingan sipil serta dapat juga digunakan untuk keperluan militer. Produk Cosat 1000 sudah banyak digunakan di berbagai wilayah Indonesia dengan berbagai tujuan diantaranya kebutuhan pertanian, pengisian waduk, kebakaran hutan, hingga acara seremonial. Produk bahan penyemai awan juga dapat digunakan sebagai salah satu strategi perang seperti yang pernah dilakukan Amerika pada perang Vietnam. Selain itu Amerika juga memanfaatkan teknologi ini untuk meredam protes massa maupun merusak hasil pertanian negara lain [12]. Dengan begitu luasnya potensi penggunaan bahan penyemai awan, maka Cosat 1000 menjadi salah satu produk unggulan yang dihasilkan dari keunggulan teknologi PT. Pindad (Persero) karena hanya sedikit produsen didunia yang mampu membuat.

Proses penyebaran bahan semai awan umumnya menggunakan tiang stasioner yang berada di ketinggian maupun dengan platform bergerak seperti pesawat terbang. Tujuan dari kegiatan tersebut adalah agar bahan kimia yang tersebar makin dekat ke awan dan bereaksi. Namun dengan perkembangan teknologi wahana udara seperti Drone maka peluang penggunaannya juga makin meningkat. Penggunaan drone sebagai wahana Teknologi Modifikasi cuaca sudah dilakukan oleh beberapa Lembaga, salah satunya The National Center of Meteorology (NCM) Uni Emirat Arab. UEA merupakan salah satu negara yang mengalami kesulitan air bersih karena curah hujan yang sedikit, sehingga kebutuhan air sangat tergantung pada air tanah. Dengan makin meningkatnya jumlah penduduk maka potensi kekeringan air juga akan bertambah. Penelitian telah menunjukkan bahwa penyemaian awan memiliki potensi peningkatan hujan hingga 35\% [13]. 


\section{KESIMPULAN}

Dari penelitian ini, dapat disimpulkan bahwa teknologi pesawat tanpa awak/ drone merupakan sebuah keniscayaan bagi bangsa Indonesia untuk dikuasai karena luas wilayah yang harus dijaga sangat luas terutama di wilayah perbatasan. Pemerintah Indonesia sudah menyiapkan program prioritas pengembangan untuk kemandirian Alutsista nasional dimana pesawat tanpa awak/ drone adalah salah satu yang harus dikuasai. Teknologi drone berperan penting sebagai platform berbagai sistem persenjataan yang nantinya akan dikembangkan dan digunakan baik untuk keperluan Operasi militer perang maupun operasi militer selain perang.

PT. Pindad (Persero) sebagai BUMN Industri Pertahanan nasional dituntut untuk berperan aktif di dalam pengembangan teknologi khususnya di bidang pertahanan nasional. Drone militer adalah platform yang saat ini menjadi salah satu prioritas utama dalam program pengembangan produk di PT. Pindad (Persero). Integrasi sistem persenjataan dengan produk Pindad yang sudah ada seperti kendaraan tempur, senjata, munisi, bom, dan perlengkapan personil akan disatukan didalam Battle Management system untuk mendukung konsep peperangan "Over The Horizon Operations". Aplikasi drone di militer akan dapat digunakan sebagai peran intelijen, pengawasan perbatasan, penambahan senjata, maupun sebagai platform serangan yang dikenal sebagai kamikaze drone. Sementara di sisi non-militer dapat digunakan untuk kebutuhan anti huru-hara dengan menggunakan gas air mata, maupun aplikasi dari teknologi penyemaian awan sebagai hujan buatan. Potensi bencana alam yang tinggi di Indonesia terutama akibat Hidrometeorologi, memerlukan pendekatan teknologi dalam mengatasi permasalahan tersebut dimana Pindad saat ini ini sudah berperan aktif dengan produk Cosat 1000. Konsep ini akan menjadi salah satu strategi penting dalam meningkatkan kemampuan pasukan Indonesia dalam menghadapi masalah yang akan muncul di masa depan.

Fleksibilitas peran yang ditunjukkan oleh kehadiran drone diharapkan dapat menjadi solusi dari berbagai permasalahan terkait kebutuhan dari pengguna itu sendiri, selain menujukkan penguasaan teknologi tinggi bangsa Indonesia kepada negara lain. Sehingga dengan luas wilayah Indonesia dimana $2 / 3$ adalah lautan dan dikelilingi oleh negara lain serta berada di daerah dengan potensi bencana yang tinggi, drone diharapkan dapat mengatasi berbagai masalah seperti illegal fishing, imigran gelap, pembajakan, banjir, kebakaran hutan, terorisme, maupun infiltrasi militer negara lain.

\section{UCAPAN TERIMA KASIH}

Ucapan terima kasih disampaikan atas diterbikannya naskah ini dalam Prosiding Seminar Nasional Sains Teknologi dan Inovasi Indonesia 2021 kepada Gubernur Akademi Angkatan Udara dengan berbagai fasilitas dan kemudahan yang telah diberikan. Demikian juga kepada Direktur PT Pindad atas kesempatan serta tiada henti memberikan motivasi, dan dorongan sehingga naskah ini dapat diselesaikan sesuai dengan rencana.

\section{REFERENSI}

[1] G. A. Rakhmat, Perancangan Dan Implementasi Battlefield Management System Pada Pertempuran Angkatan Darat, Program Studi Manajemen Informatika, Politeknik Praktisi Bandung.

[2] Lickteig, Carl W., "Design Guidelines and Functional Specifications for Simulation of the Battlefield Management System's (BMS) User Interface", ARI Field Agent, July, 1988.

[3] PEMODELAN AGENT PERANG PADA SIMULASI BATTLEFIELD MANAGEMENT SYSTEM Ketut Abimanyu Munastha Program Studi Teknik Elektro Universitas Sangga Buana YPKP Bandung, Jurnal Infotronik Volume 1, No. 1, Desember 2016.

[4] Jeffrey J. Smith, Beyond the Horizon: Developing Future Airpower Strategy, Strategic Studies Quarterly, Vol. 8, No. 2 (SUMMER 2014), pp. 74-95, Air University Press 
[5] G. Battsengel, S.Geetha and J. Jeon, Analysis of Technological Trends and Technological Portfolio of Unmanned Aerial Vehicle, J. Open Innov. Technol. Mark. Complex. 2020, 6, 48;

[6] Gupta, L.; Jain, R.; Vaszkun, G. Survey of Important Issues in UAV Communication Networks. IEEE Commun. Surv. Tutor. 2016, 18, 1123-1152.

[7] A. Sud, UAVs and Counter UAVs Technologies in the World and the Indigenous Capability, CLAWS Journal, Summer 2020

[8] W. Zwijnenburg and F. Postma, Unmanned Ambitions Security implications of growing proliferation in emerging military drone markets, PAX, 2018.

[9] "These 6 Drones Are Ready and Waiting To Tear Gas You". https://www.popularmechanics.com/flight/drones/g2445/tear-gas-capable-drones/ (accessed Nov. 10, 2021).

[10] "Is the use of unmanned military drones ethical or criminal?". https://www.theguardian.com/commentisfree/video/2013/dec/02/unmanned-military-drones-battle-ethicalvideo-debate (accessed Nov. 10, 2021).

[11] Neuneck, G., \& Alwardt, C. The Revolution In Military Affairs, Its Driving Forces, Elements and Complexity. IFSH IFAR. 2008. Retrieved from Wiley.com: https://onlinelibrary.wiley.com/doi/abs/10.1002/cplx.20236

[12] J. R. Fleming, The Climate Engineers. 2007. Retrieved from Colby.edu: https://www.colby.edu/sts/climateengineers.pdf

[13] Heitmann, A. Cloud Seeding Technology: How Drones Can Create Rainfall. 2021. Retrieved from Borgen Magazine: https://www.borgenmagazine.com/cloud-seeding/ 